Funding: This work was supported by the MRC Health Services Research Collaboration.

Competing interests: None declared.

Crow R, Gage H, Hampson S, Hart J, Kimber A, Thomas H. The role of expectancies in the placebo effect and their use in the delivery of health care: a systematic review. Health Technol Assess 1999;3(3):1-96.

2 Grunbaum A. Explication and implications of the placebo concept. In White L, Tursky B, Schwartz GE, eds. Placebo theory, research, and mechanisms. New York: Guilford Press, 1985:9-36.

Hrobjartsson A. What are the main methodological problems in the estimation of placebo effects? J Clin Epidemiol 2002;55:430-5.

4 Di Blasi Z, Harkness E, Ernst E, Georgiou A, Kleijen J. Influence of context effects on health outcomes: a systematic review. Lancet 2001;357:75762.

5 Paterson C, Britten N. In pursuit of patient-centred outcomes: a qualitative evaluation of MYMOP, measure yourself medical outcome profile. $J$ Health Serv Res Policy 2000;5:27-36.

6 Paterson C, Britten N. Acupuncture for people with chronic illness: combining qualitative and quantitative outcome assessment. I Altern Complement Med 2003.5.671-81.

7 Paterson C, Britten N. Acupuncture as a complex intervention: a holistic model. J Altern Complement Med 2004;10:791-801.

Moerman D. Meaning, medicine and the placebo effect. Cambridge: Cambridge University Press, 2002.

9 Lewith G, Walach H, Jonas WB. Balanced research strategies for complementary and alternative medicine. In: Lewith $\mathrm{G}$, Jonas WB, Walach $\mathrm{H}$, eds. Clinical research in complementary therapies. Principles, problems and solutions. Edinburgh: Churchill Livingstone, 2002:1-28.

10 Johannessen $\mathrm{H}$. Individualized knowledge: reflexologists, biopaths and kinesiologists in Denmark. In: Cant S, Sharma U, eds. Complementary and alternative medicines: knowledge in practice. London: Free Association Books, 1996:116-34.

11 Power R. Only nature heals: a discussion of therapeutic responsibility from a naturopathic point of view. In: Budd S, Sharma U, eds. The healing bond. London: Routledge, 1994:193-213.

12 Kleijen J, de Craen AJM, van Everdingen J, Krol L. Placebo effect in double-blind clinical trials: a review of interactions with medications. Lancet 1994;344:1347-9.

13 Barfod TS. Placebo therapy in dermatology. Clin Dermatol 1999;17:69-76.

14 Bootzin RB, Caspi O. Explanatory mechanisms for placebo effects: cognition, personality and social learning. In: Guess HA, Kleinman A, Kusek JW, Engel LW, eds. The science of the placebo. Toward an interdisciplinary research agenda. London: BMJ Books, 2002:108-32.

15 Kaptchuk TJ Edwards RA, Fisenberg DM. Complementary medicine: efficacy beyond the placebo effect. In: Ernst E, ed. Complementary medicine: an objective appraisal. Oxford: Butterworth Heinmann, 1996:31-41.

16 Mason S, Tovey P, Long AF. Evaluating complementary medicine: methodological challenges of randomised controlled trials. BMJ 2002; 325:832-4.

17 White AR, Filshie J, Cummings TM. Clinical trials of acupuncture: consensus recommendations for optimal treatment, sham controls and blinding. Complement Ther Med 2001;9:237-45.

18 Birch S. Clinical research on acupuncture. Part 2: Controlled clinical trials, an overview of their methods. J Altern Complement Med 2004;10: $481-98$.

19 Grencavage LM, Norcross JC. Where are the commonalities among the therapeutic common factors? Prof Psychol Res Pract 1990;21:372-8.

20 Quilty B, Tucker M, Campbell R, Dieppe P. Physiotherapy, including quadriceps exercises and patellar taping, for knee osteoarthritis with predominant patello-femoral joint involvement: randomised controlled trial. J Rheumatol 2003;30:1311-7.

(Accepted 24 February 2005)

\title{
GMC and the future of revalidation Building on the GMC's achievements
}

Graeme Catto

Revalidation is under scrutiny. The GMC plans to play an important part in developing an effective system

The fifth report of the Shipman inquiry provided a thorough and considered analysis of the issues surrounding fitness to practise. ${ }^{1}$ We must all approach the report in the spirit of learning from the past and as a source of ideas for improving the protection of patients in the future. The government's proposals to improve death certification and for tighter regulation of controlled drugs ${ }^{2}$ will, alongside clinical governance, help stop another Harold Shipman. Nevertheless, the General Medical Council recognises that further changes are required to our processes.

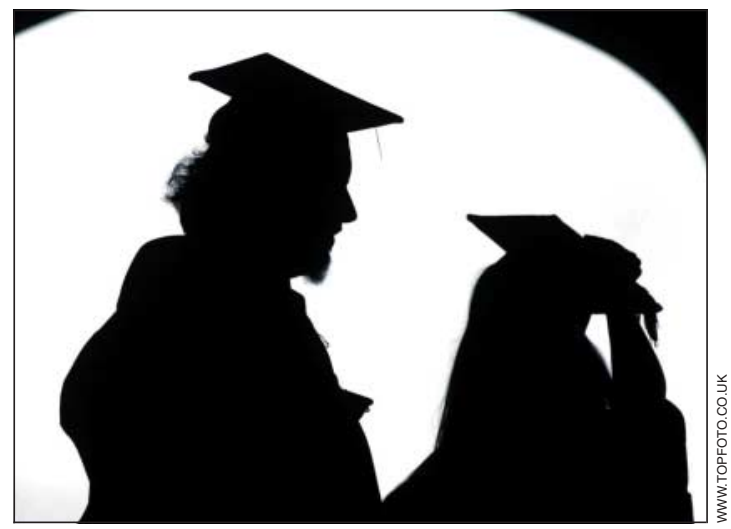

How can we ensure new doctors remain fit to practise?

\section{Lessons from the inquiry}

Some have argued that no general lessons can be drawn from the Shipman case. I believe that view is mistaken. Of course many of the circumstances were specific, but much broader, historical issues were raised. These include:

- The absence of local systems that could detect emerging poor, dangerous, or criminal practice and take effective action at an early stage before patients came to harm

- Uncertainty among patients about how to pursue a concern about a doctor, together with a profound feeling of disempowerment

- Reluctance by some professionals to admit even the possibility that a doctor might be putting patients seriously at risk

- Lack of coherence and coordination between the roles of the NHS and the GMC in protecting patients

- And the lack of robust and systematic arrangements to verify that doctors are up to date and fit to practise.

Dame Janet Smith, the chairman of the inquiry, acknowledged that much has changed for the better, but we all have more to do, whether within our regulatory bodies, healthcare organisations, or clinical teams or as individual healthcare professionals. We need to ensure that further changes build on what has already
This is the second in a series of articles examining the regulation of doctors

General Medical Council, London NW1 3JN

Graeme Catto president opce@gmc-uk.org BMJ 2005;330:1205-7 
been achieved. The review by the chief medical officer for England provides an opportunity to consider what is still required. We should not change for the sake of change, but momentum in delivering necessary reform must be maintained.

\section{Inquiry and the GMC}

But before we move on to the review, I think it helpful to reflect on aspects of the fifth report that some have overlooked. The inquiry's main task was to determine how Shipman remained free to murder for so long. It concluded, emphatically, that the GMC cannot be held responsible for that. Dame Janet made 109 recommendations. Almost half relate to the NHS, covering matters such as handling of complaints and NHS appraisal. Of those that relate to the GMC, many are technical.

The inquiry had no remit to consider revalidation in the context of the GMC's other roles. (No evidence was taken on our pivotal role in medical education, in standards and ethics, in ensuring that the 12000 doctors who come on to the register each year are fit to practise, or in our international work.) It explicitly endorsed our view that a professional majority on the GMC is essential, alongside strong lay involvement in all our work, and that the GMC, while continuing to be independent of government, should be directly accountable to parliament. However, the inquiry made important recommendations about handling the adjudication of complaints against doctors, our plans for revalidation, and the number of directly elected members of the council, which according to the report should not form a majority.

Our reformed fitness to practise procedures, introduced in November 2004, will result in improvement, and Dame Janet has made recommendations to strengthen them further. Indeed, during the inquiry she commented on matters such as sharing of information and transparency, which we were able to incorporate into those reforms.

The existing position is that specially trained panels of medical and lay people, on which GMC council members no longer sit, make final decisions on fitness to practise. Dame Janet raised concerns about the compatibility of these arrangements with the European Convention on Human Rights. At the time the legislation was passed, the government confirmed that the arrangements are compatible. But the wider implications of totally separating out adjudication need to be considered in the review.

In any system depending on judgment, the decision makers sometimes get it wrong. However, I do not recognise the picture some are painting of an organisation that is less than whole hearted in protecting patients. As regulation requires the confidence of all partners, I am glad that the governance of the GMC is being considered as part of the review.

The fitness to practise procedures have a high public profile, but they will affect a tiny percentage of registered doctors. That is because the majority of doctors deliver a conscientious, professional service in a rapidly changing social and organisational environment. For them, it is the plans for revalidation that will be of greatest interest. Nevertheless, we must continue to work with others for the earlier and more effective identification of dysfunctional practice. The system also needs to show that the overwhelming majority of doctors are working safely and effectively, to encourage continued improvements, and to defend good standards of professional practice. That is why the GMC, together with the Department of Health and other partners, developed revalidation.

From the start, the aim of revalidation has been to enable doctors to show that they are up to date and fit to practise, and to encourage improvement through meaningful reflection based on evidence drawn from practice. I cannot improve on this description by my predecessor: "Revalidation is based on the positive affirmation of good practice rather than the negative identification of bad apples."

No one striving to devise a system to identify poor performance would propose a system based on a five yearly review, with up to five years elapsing before such problems were brought to light. This is especially true when separate arrangements to detect poor performance are already being put in place through clinical governance and are operating with increasing effectiveness. That is why, in May 2001, my predecessor wrote to the BMA to say that, provided the NHS appraisal process was robustly and effectively implemented, appraisal documentation would be the vehicle for revalidation for the majority of NHS consultants and other groups of doctors who have appraisal systems.

The qualification "robustly and effectively" was prescient. The GMC subsequently recognised that participation in appraisal alone would not provide the required assurance about fitness to practise; we therefore developed the concept of clinical governance certification. This would mean that, within each NHS organisation, a senior person with clinical governance responsibilities would be required to certify that the doctor was fit to practise on the basis of verifiable evidence brought together locally.

Dame Janet took the view that the GMC was overrelying on appraisal. She believed that the addition of local certification was a move in the right direction, although she criticised it for being a "negative certificate," saying only that nothing adverse was known. (We see the principle of certification as capable of providing positive affirmation of fitness to practise.) Taken with the other concerns expressed about both revalidation and appraisal, she concluded that the proposed arrangements would not provide the level of confidence necessary.

It is important to recognise that, far from breaking the linkage between revalidation and clinical governance, Dame Janet has recommended that it should be strengthened. The review will no doubt suggest how this should be done. The GMC needs to be assured that, whatever their precise form, the arrangements that underpin revalidation are robustly and effectively implemented. Dame Janet has not proposed an alternative revalidation model, no doubt because no such model is available that would be practicable and not impose disproportionate burdens on doctors with corresponding unacceptable consequences for patient care.

I want revalidation to be implemented as soon as possible. However, the whole point of revalidation is to increase public confidence that doctors are up to date 
and fit to practise, and it would have been pointless to press ahead without first dealing with the doubts that have been raised. I have therefore supported postponement. But confidence can be fragile. It will not have been helped by some of the reporting in the aftermath of the inquiry and the spinning going on around it. In public life you get used to that, and to some people reaching conclusions on the basis of anecdotes. The solid evidence from our consultation should not be overlooked. It showed widespread support in the UK and abroad for our revalidation proposals. Although they can undoubtedly be strengthened, let us not overlook that the UK medical profession has taken the lead by developing revalidation. Nothing in the fifth report detracts from that, and nothing in it undermines the principles that underpin revalidation.

\section{Moving forward}

Continuing to debate the past would be unproductive. What counts now is to get revalidation right for the future. The GMC will contribute positively to the review. We see several areas where we can do so. The first is in being more explicit about the evidence that doctors must include in their revalidation folders. Dame Janet has made helpful suggestions that although intended for general practitioners, would apply to most doctors working in a clinical setting-for example, folders should include prescribing data and records of complaints and concerns, information about continuing professional development, the results of audit, and a patient satisfaction questionnaire. We expect that these would be covered within appraisal or through clinical governance systems. The emphasis, I believe, must be on performance in practice.

The GMC also has a role in developing the quality assurance framework. We have already described the characteristics of a GMC approved environment. We expect that most NHS organisations will meet our requirements but some may not. We cannot rely safely on local systems unless explicit quality assurance arrangements are in place, and we need to be more explicit about how they will operate. We also need to be

\section{Summary points}

The primary purpose of revalidation is to certify fitness to practise

The Shipman inquiry made recommendations for improving the GMC's revalidation model

The GMC intends to develop explicit requirements for validation and quality assurance

The GMC will also continue to work with others to detect poorly performing doctors and ensure early action

clearer about how, and with what purpose, we will operate random and targeted sampling.

Although revalidation is the affirmation of a positive, we have always said that the GMC must also contribute, with clinical governance systems, to the detection of, and early action on, problem doctors. We need to further develop proposals to make this clearer, and we see a much closer cooperation with employers as the key.

The reformed GMC will continue to force the pace of reform and take whatever steps are necessary to play our part in delivering patient led healthcare and to fulfil our statutory purpose "to protect, promote and maintain the health and safety of the public."

Contributors and sources: GC has been a member of the GMC since 1994 and has served on its education committee and committee on professional performance. He is also a member of the Council for Healthcare Regulatory Excellence.

Competing interests: None declared.

1 Shipman Inquiry. Safeguarding patients: lessons from the past-proposals for the future. www.the-shipman-inquiry.org.uk/fifthreport.asp (accessed 19 Apr 2005)

2 Department of Health, Home Office. Safer management of controlled drugs: the government's response to the fourth report of the Shipman inquiry. 2004. www.dh.gov.uk (search for $\mathrm{Cm}$ 6434).

3 Irvine DH. The doctors' tale: professionalism and public trust. Oxford: Radcliffe Medical Press, 2003.

\section{Cardiologists embrace new terminology}

Viewed from the plain speaking world of general practice, cardiologists seem to be rivalling dermatologists in developing an ever changing array of terms for conditions they encounter. One particularly disingenuous example recently came my way.

Five years ago, our practice purchased an automated defibrillator. In the six months before its arrival, I had had need of one on two occasions. For five years after its arrival, it stood unused in the corner of an alcove. Until, that is, a 70 year old man attended his Monday morning appointment with our practice nurse to have a sutured finger redressed. Commendably, he had parked half a mile from the surgery and walked briskly across town for some exercise. On entering the waiting room, he collapsed. In a surprisingly calm and organised manner he was resuscitated by a GP and two nurses, while receptionists marshalled the absorbed onlookers and telephoned for an ambulance. Our defibrillator restored sinus rhythm with its first shock.

The patient was admitted to hospital, transferred to a tertiary centre for insertion of an implantable defibrillator, and discharged. He continues to attend for six monthly review at our practice and remains active and well. A discharge summary followed with the usual delay. The primary diagnosis? Not "Successful out-of-hospital resuscitation" or "VF successfully defibrillated" but rather "Failed sudden cardiac death."

Crispin Fisher general practitioner, Marches Surgery, Leominster (crispin.fisher@nhs.net) 